\title{
A NOVEL TENT POLE TECHNIQUE FOR HARD TISSUE AUGMENTATION AROUND DEFICIENT ALVEOLAR RIDGES - A NARRATIVE REVIEW
}

\author{
Dr. J.Arun Kumar, Dr. R. Kadhiresan, Dr. U. Arunmozhi, Dr. Shanmuga Priya, Dr.R.A. Jenifer Cynthia
}

Department of Periodontology and Oral Implantology, Sri Venkateswara Dental College and Hospital, Off OMR road, Near

Navalur, Thalambur, Chennai-603103

DOI: 10.37841/jidam_2021_V8_14_04

Address for Correspondence:

Dr. J.Arun Kumar,

Post Graduate Student,

Department of Periodontology and Oral Implantology

Sri Venkateswara Dental College and Hospital

Off OMR road, Near Navalur, Thalambur, Chennai-603103

E-mail: arun31796kumar@gmail.com

Received: 05.12.2021

First Published: 21.12.2021

Accepted: 20.12.2021

Published: 27.12.2021

\section{ABSTRACT}

Consequences of missing teeth which involves impairment in esthetic and masticatory functions. Replacement of missing teeth using either removable or fixed prosthesis will require a adequate bone support. Due to various causes such as dental caries, periodontitis, trauma which leads to extraction of teeth. Naturally the alveolar bone is maintained by the presence of teeth that it retains. After extraction, the alveolar bone resorption occurs both in height and width of the residual ridge which is inevitable. In patients with insufficient bone height and width, the placement of dental implants in an ideal position is very difficult. It is necessary to restore the alveolar ridge anatomy for successfully placing implants. Various surgical techniques have been introduced to augment the lost bone and one of such technique is Tent Pole technique.

KEY WORDS: Guided bone regeneration, Ridge augmentation, Tent pole technique 


\section{INTRODUCTION}

Consequences of missing teeth which involves impairment in esthetic and masticatory functions. Replacement of missing teeth using either removable or fixed prosthesis will require a adequate bone support. Due to various causes such as dental caries, periodontitis, trauma which leads to extraction of teeth. Naturally the alveolar bone is maintained by the presence of teeth that it retains. After extraction the alveolar bone resorption occurs both in height and width of the residual ridge which is inevitable. The rate of progression of bone loss follows a distinctive pattern in which bone is lost in logarithmic declining fashion. So, higher resorption rate is seen in the early post extraction phase. This alveolar atrophy leads to decrease in height and width of the available ridge. In patients with insufficient bone height and width, the placement of dental implants in an ideal position is very difficult. It is necessary to restore the alveolar ridge anatomy for successfully placing implants. Various surgical techniques have been introduced to augment the lost bone and one of such technique is Tent Pole technique ${ }^{1}$. This review aims to describe the various indications and advantages of tenting pole technique .

\section{CLASSIFICATION OF RIDGE DEFECTS}

Classification methods are usually made to create guiding principle for management of a specific condition in clinical practice

\section{Seibert's classification $(1983)^{2}$}

Class I - Loss of buccolingual width but normal apicocoronal height.

Class II- Loss of apicocoronal height but normal buccolingual width.

Class III - A combination of both buccolingual and apicocoronal loss of the ridge (both height and width)

\section{Allen's classification $(1985)^{3}$}

Allen introduced severity as a classification criterion in the evaluation of alveolar deformities. The ridge deformity was described by evaluating depth of the defect relative to the adjacent ridge.

- Mild: $<3 \mathrm{~mm}$

- Moderate: 3 to $6 \mathrm{~mm}$

- Severe: $>6 \mathrm{~mm}$

\section{Misch and Judy's classification(1987)}

It describes four divisions according to available bone height, width and angulation

A. Abundant bone- $>5 \mathrm{~mm}$ in width, 10 to $13 \mathrm{~mm}$ in height and $>7 \mathrm{~mm}$ in length.

B. Barely sufficient bone -2.5 to $5 \mathrm{~mm}$ in width, $>10$ to 13 $\mathrm{mm}$ in height and $>12 \mathrm{~mm}$ in length

C. Compromised bone $-<2.5 \mathrm{~mm}$ in width

D. Deficient bone - Bone is insufficient that requires hard tissue augmentation and is usually not acquiescent to implant rehabilitation

Elian, Cho etal $(2007)^{5}$

Types Ia -Extraction sockets without hard-tissue defect by thick gingival biotype

Type Ib- Extraction sockets without hard-tissue defect thin gingival biotype

Type II-with buccal bone defects

Type III-generalized defect situations

\section{The Cologne Classification of Alveolar Ridge Defects (CCARD 2013) ${ }^{6}$}

Part 1: Orientation of the defect
H: horizontal
V: vertical
C: combined
$\mathrm{S}($ or $+\mathrm{S})$ : sinus area

Part 2: Reconstruction needs associated with the defect
1. low: $<4 \mathrm{~mm}$
2. medium: $4-8 \mathrm{~mm}$
3. high: $>8 \mathrm{~mm}$ )

Part 3: Relation of augmentation and defect region

i: internal, inside the contour

e: external, outside the ridge contour 
Tolstunov L. Classification of the alveolar ridge deficiency (2014).$^{7} \quad($ Fig 1a \& 1b)

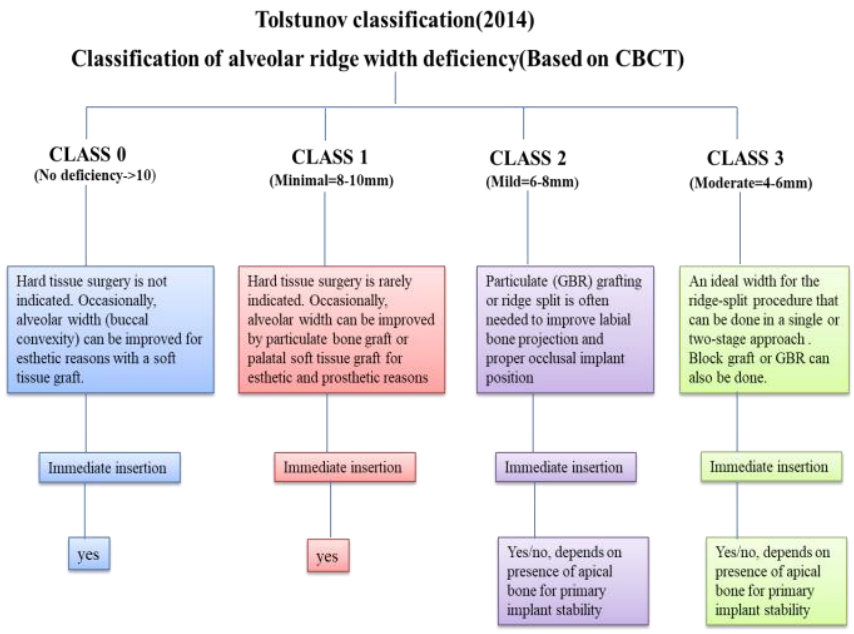

Fig 1a: Tolstunov L. Classification of the alveolar ridge deficiency (2014)
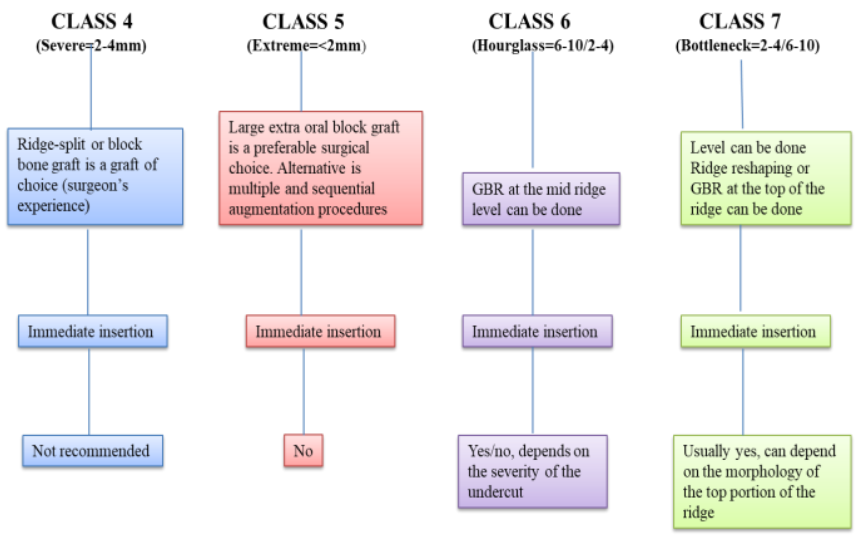

Fig 1b: Tolstunov L. Classification of the alveolar ridge deficiency (2014)

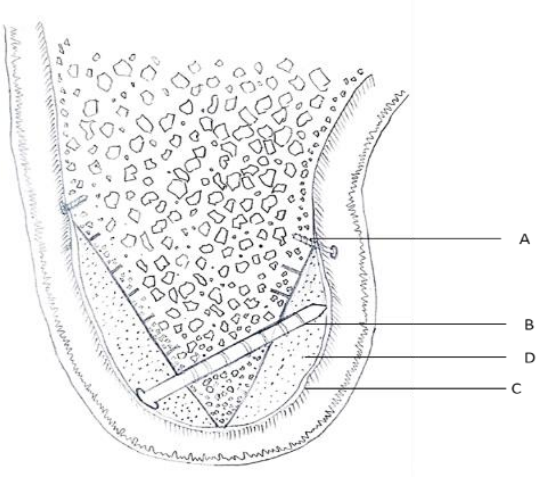

Fig 2: TENTING POLE TECHNIQUE: A-membrane tac screws, B-Tenting screw, C-Bone graft, D-membrane barrier.

\section{CONVENTIONAL RIDGE AUGMENTATION TECHNIQUES}

The main aim of ridge augmentation techniques is to re-establish sufficient quantity of bone dimensions for placement of implants; to re establish inter maxillary ridge correlation; to achieve esthetics and biomechanical requisite of the prosthesis. There are various ridge augmentation techniques such as inlay grafting, onlay grafting, alveolar distraction osteogenesis, guided bone regeneration.

\section{PARTICULATE GRAFT:}

Different types of bone grafts like autograft, allograft, xenograft and alloplast were used in the augmentation of alveolar bone. Particulate bone graft of different sizes can be used alone or mixed with other type for increasing the height and width of alveolar bone. Due to lack of attachment to the defective site there were some failure. To overcome the graft rejection or failure other techniques were introduced.

\section{BLOCK GRAFTS:}

Autogenous block graft augmentation of the alveolar ridge is a reliable strategy for augmenting localised alveolar ridge deficiencies, although it can be challenging in large 3dimensional defects. Furthermore, because there is a limited supply of intraoral donor bone, these large atrophic portions present a more difficult restoration scenario. Extra oral donor sites are an option, but the extra expenses and morbidity make them very unpopular with patients ${ }^{8}$.

\section{DISTRACTION OSTEOGENESIS:}

Vertical ridge deficits are treated with alveolar ridge reconstruction using distraction osteogenesis. Using intra or extraoral osseous devices, ADO can be conducted in a single or several directions. This procedure can achieve a bone height of more than $12 \mathrm{~mm}$. The following are the key advantages of this approach. Bone blood flow is maintained, there is little chance of infection, and there is little bone resorption and soft tissue gain. Patient compliance and expense are the two biggest drawbacks. During distraction and consolidation periods, several soft tissue changes occur. When a considerable amount of bone needs to be obtained, it is advisable to divide the complete amount of distraction across multiple time periods rather than diverting the bone all at once? .

\section{ONLAY BONE GRAFTING:}

It is the process of placing and fixing bone grafts on the alveolar ridge's surface. Block or Particulate onlay bone grafts can be used. Titanium mesh can also be used for 
localised alveolar ridge augmentation. The deficiency was evaluated histologically, histomorphometrically, and radiographically and demonstrated adequate bone height growth for implant placement. The bone grafts' thickness should be slightly greater than the intended width or thickness. To allow for contouring, adaptation, and graft resorption, the graft should be 3-4 $\mathrm{mm}$ larger than the recipient site. Because they show less resorption, onlay block grafts have a higher structural integrity than particle bone grafts. Infection, soft tissue abnormalities, graft exposure owing to soft tissue dehiscence, loss of grafting material, and insufficient bone volume are all risks associated with conventional grafting ${ }^{9}$.

\section{GBR:}

GBR (Guided Bone Regeneration) is a predictable therapeutic procedure that can be used alone to increase the ridge in a staged approach or in conjunction with implant insertion when primary implant stability is needed. This treatment involves filling the defect with bone grafts and/or bone replacements, then enclosing the material with a barrier to keep epithelial and gingival connective tissue cells out. Due to the increased tissue regeneration, bony defects can be corrected in 6-10 months. Two probable outcomes are membrane exposure or early membrane disintegration. It's mainly intended for abnormalities that necessitate a vertical bone augmentation of 2-7 $\mathrm{mm}$.

\section{PAST APPROACHES TO CORRECT SEVERELY RESORBED MANDIBLE}

The first well-documented series on the reconstruction of severely resorbed mandibles was published by Baker et al. in 1979. These researchers discovered $50 \%$ graft resorption after one year and $75 \%$ graft resorption after 18 months when autogenous rib grafts were used as onlay grafts.

Davis et al., observed that only $34 \%$ of the original graft height remained over a long period of time. According to these researchers, resorption is involved in the development and contraction of underlying soft tissue. The grafts lost most of their original height, leaving a broad flat ridge with tight, hard soft tissue covering it.

Stoelinga et al. proposed the concept of combining horizontal alveolar osteotomy with bone grafting and termed it "sandwich osteotomy" in the anterior mandible during the same time period. Early consequences of this treatment included fractures at the osteotomy joints, sensory nerve loss, discomfort, and nonunions.

Later on, Harle publicized the concept of vertical osteotomy with bone grafting, sometimes known as "visor osteotomy."
This procedure also resulted in fractures, discomfort, nonunion, and sensory nerve loss.

By 1980, several writers had introduced Hydroxyapatite (HA) as blocks, particles, and root form implants. Soft tissue contraction occurred over an avascular foreign body in the case of HA blocks, resulting in poor healing of oral incisions and subsequent dehiscence. The HA particles were also forcibly displaced by soft tissue contraction, which frequently resulted in a considerable fibrosis surrounding the mental nerve, leading in neuropathies characterised by sensory loss or pain.

\section{LIMITATIONS:}

Premature removal, exfoliation, and the need for a second surgical treatment to remove them.

Exposure of the grafts, infection, integration failure, and late bone resorption are all possible outcomes. These issues could result in the graft being completely lost.

\section{TENT POLE TECHNIQUE:}

In order to gain bone height and width, various techniques were used before. There were several drawbacks as mentioned. In order to overcome these drawbacks, a novel method called TENT POLE technique was first introduced by Marx et al (2002). TENT POLE technique can be successfully used in Sieberts class I, II and III bony defects. Any patients with uncontrolled diabetes mellitus or any other bony disorders is not indicated for this technique.

The main requisites for this technique are: Bone grafts, membranes and Tenting Screws. Bone grafts such as allografts, xenografts and autografts can be used either alone or in combination as composite graft in the form of block or particulate. Membranes used to hold the graft in its position which can be of Resorbable collagen membrane or non-resorbable ePTFE membrane or even PRF also can be used to promote healing. Membranes can be used to prevent downward movement of the epithelium in to the graft which prevents fibrous bony formation. Tenting screws are of various dimensions $1.5-3 \mathrm{~mm}$ width and $8-12 \mathrm{~mm}$ length. Proper selection of tenting screws depends upon the size of the defect and the amount of height and width of the alveolar bone required. Various sizes of tenting screws ranging from $1.5-3.5 \mathrm{~mm}$ width and $6-10 \mathrm{~mm}$ in length.

\section{SURGICAL PROCEDURE:}


The surgery is performed under strict infection control. Under local anesthesia, crestal incisions are made along with vertical Reliving incision in mesial and distal side of the defective area. Full thickness mucoperiosteal flap reflection will be done using $\mathrm{BP}$ blade or periosteal elevator. Defective area can be debrided using curettes. Tent screws placed in the bone with adequate spacing inbetween and the required length should be exposed outside .The bone decortication can be done using surgical round bur to initiate fresh bleeding as well as for better adherence of the graft. Decortication helps in inducing osteogenic potential with in the bone.

This screw has a cutting edge at the tip and smooth edge near the head. The cutting edge helpful in engagement of screw in bone and the smooth surface will be used to hold the graft in its position.

After placing the tenting screws the bone grafts either a single type or a composite graft will be placed and resorbable or a non resorbable membrane used to cover the defect .Bone grafts are well condensed in to the defective sites till the head of the tenting screws. Either the membranes will be placed over the graft or will be attached to the bone using stabilization screws. Either non resorbable or resorbable sutures will be placed depends upon individual preferences. It is an open approach in which tenting screws are inserted into the defect and a bone graft is packed around the screws before a resorbable collagen membrane is used to fill the defect. This technique would allow for the grafting of large, 3-dimensional, vertical and horizontal segments without the requirement for extraoral or intraoral bone harvesting. The screws, in combination with bone grafts, could be employed as an osteoconductive scaffold to reconstruct significant ridge deficiencies, resulting in enough bone quantity and quality after 4 to 5 months to allow for endosseous implant osseointegration ${ }^{10 \mathrm{~s}}$. (Fig 2)

\section{DISCUSSION:}

Marx, Shellenberger, Wimsatt, and Correa (2002) hypothesised that the major theme in these failed techniques was a lack of soft tissue volume, which then contracted following surgical expansion when a graft was placed, as well as a failure to provide enough bone stock to prevent fracture. Onlay grafts to these severely resorbed mandibles were physiologically resorbed due to the remodelling process, resulting in a net loss of bone due to soft tissue volume contraction around the graft. As a result, long-term control and maintenance of surgically enlarged soft tissue volume should avoid graft resorption.
The authors documented the outcomes of 64 cases of bone grafts using the implant tenting approach, all of which were followed for at 3 years. Before surgery, the vertical mandible height ranged from 2 to $6 \mathrm{~mm}$. After surgery, the bone height remained unchanged at $15 \mathrm{~mm}$. The increase in bone height was 9 to $13 \mathrm{~mm}$ on average, with a mean of $10.2 \mathrm{~mm}$. Eight people had unilateral mental nerve paresthesia for three weeks, while three people had bilateral mental nerve paresthesia for three weeks. There were no reports of long-term paresthesia. The bone grafts were found to maintain their bone height and become more radiographically dense over time in all patients. 356 dental implants were implanted in these 64 instances, with 354 osseointegrated $(99.5 \%)$ and functioning at the time of follow-up (>3 years) ${ }^{11}$.

In a study published in 2008, Lee B, Burstein J, and Sedghizadeh evaluated the efficiency of intraoral cortical bone grafts in combination with particulate human mineralised allograft in large vertical alveolar lesions in a "tenting" method. This study included ten patients who had substantially resorbed alveolar ridges and were missing at least four neighbouring teeth. In a tenting procedure, cortical bone graft and human mineralised allograft were used to increase the ridge. 4-5 months following augmentation, the ridges were clinically assessed. At the time, 42 implants were implanted. The osseointegration of the implants was tested. One of the implants did not osseointegrate. After a year, all of the augmented ridges had maintained their functional and aesthetic integrity ${ }^{12}$.

Korpi, Sandor, Kainulainen, Oikarinen (2012) published a study on long term follow up of severely resorbed mandible reconstructed using tentpole technique without platelet rich plasma (PRP). The study included 22 healthy patients (3 males and 19 women) who had an edentulous mandible with a vertical height of $6 \mathrm{~mm}$ or less and a history of conservative prosthodontic treatment failures, ranging in age from 51 to 72 years. Endosseous dental implants were inserted in the anterior mandible's alveolar ridge and covered with cancellous bone grafts taken from the posterior iliac crest without the use of PRP. The study was followed up on for 3-9 years. The postoperative period went without a hitch, and no surgical infection was found. Three months after surgery, an orthopantamogram revealed that the grafted bone density was similar to that of the surrounding alveolar bone. At the peak of the alveolar ridge, the bone height was the same as the height of the dental implant. The average augmentation of the alveolar ridge was $6.3 \mathrm{~mm}$. Only two patients had mental nerve paresthesia shortly after surgery, and only one patient had minor long-term unilateral nerve sensitivity disruption. A 
Arun et al: A Novel Tent Pole Technique for Hard Tissue Augmentation

total of 88 dental fixtures were installed, with 86 of them having the proper axial tilt. For appropriate abutment placement and hygiene, 5 of 88 sites required hyperplasic soft tissue excision at the time of re-entry. The lack of a control group in this research made determining the role of $\mathrm{PRP}$ in this technique is problematic ${ }^{13}$.

\begin{tabular}{|c|c|c|c|c|c|c|}
\hline Authors & No. of cases & $\begin{array}{l}\text { Presurgical } \\
\text { height }\end{array}$ & $\begin{array}{l}\text { Bone } \\
\text { augmentation } \\
\text { achieved }\end{array}$ & $\begin{array}{l}\text { No. of implants } \\
\text { placed }\end{array}$ & $\begin{array}{l}\text { No. of implants } \\
\text { osseointegrated }\end{array}$ & Complications \\
\hline $\operatorname{Marx}(2002)$ & 64 & $2-6 \mathrm{~mm}$ & $9-13 \mathrm{~mm}$ & 356 & 354 & $\begin{array}{l}\text { Short term } \\
\text { mental nerve } \\
\text { paresthesia in } \\
8 \text { pts. }\end{array}$ \\
\hline Lee (2008) & 10 & NA & NA & 42 & 41 & NA \\
\hline $\begin{array}{l}\text { Lee, Rohrer and } \\
\text { Prassad (2010) }\end{array}$ & 15 & $3-6 \mathrm{~mm}$ & $9.7 \mathrm{~mm}$ & 32 & 32 & $\begin{array}{l}\text { Wound } \\
\text { dehiscence in } 2 \\
\text { pts }\end{array}$ \\
\hline Korpi (2012) & 22 & $<6 \mathrm{~mm}$ & $4-10 \mathrm{~mm}$ & 88 & 86 & $\begin{array}{l}\text { Mental nerve } \\
\text { paresthesia in } \\
2 \text { pts }\end{array}$ \\
\hline Kuoppala (2013) & 17 & NA & NA & 67 & 65,2 lost & $\begin{array}{l}\text { Short term } \\
\text { mental nerve } \\
\text { paresthesia; } \\
\text { pain at graft } \\
\text { donor site }\end{array}$ \\
\hline FdiuDaga(2017) & 20 & NA & $2.5-3 \mathrm{~mm}$ & 31 & 31 & NA \\
\hline $\begin{array}{l}\text { Tu Lam } \\
\text { Doan }(2020)^{14}\end{array}$ & 6 & $2-4 \mathrm{~mm}$ & $5-8 \mathrm{~mm}$ & 9 & 9 & NA \\
\hline Gozde isik(2021) $)^{15}$ & 13 & NA & $\begin{array}{l}1.72 \pm \\
0.78 \mathrm{~mm}\end{array}$ & NA & NA & $\begin{array}{l}\text { Screw } \\
\text { exposure, } \\
\text { screw fracture }\end{array}$ \\
\hline
\end{tabular}

\section{ADVANTAGES:}

To enhance the efficacy of space creation, the use of a screw or pin protruding a few millimetres from the host bone in conjunction with GBR will offer actual support for the membrane and prevent it from collapsing, compromising the GBR outcome.

Screw-tenting is mostly used for horizontal augmentation, while tent-pole technique is used to gain bony height.

\section{LIMITATIONS:}

The procedure is not suitable for vertical augmentation, horizontal augmentation of atrophic ridges (3-dimensional restoration), or extensive defects because to the high rate of bony resorption.

Dehiscence or infection of the wound, as well as exposure of the screw, were the most serious consequences.

\section{CONCLUSION:}

Tenting pole technique helps in ridge width gain, grafting material resorption, and reduces post-operative problems.

This also allows for predictable functional and aesthetic reconstruction of vertical and horizontal defects with the use of bone grafts that support subsequent implant placement.

More research is needed to fully evaluate bone augmentation using the screw tent-pole technique, with different graft materials and larger samples.

\section{FINANCIAL SUPPORT AND SPONSORSHIP}

Nil

\section{CONFLICTS OF INTEREST}

There are no conflicts of interest. 


\section{REFERNCES:}

1. Daga, Dipti \& Mehrotra, Divya \& Mohammad, Shadab \& Chandra, Shaleen \& Singh, dr geeta. Tentpole technique for bone regeneration in vertically deficient alveolar ridges: A prospective study. Journal of Oral Biology and Craniofacial Research 2017. s8.10.1016/j.jobcr.2017.11.002.

2. Seibert JS. Reconstruction of deformed partially edentulous ridges, using full thickness onlay grafts. Part I Technique and wound healing. Compend Cont Ed Gen Dent 1983;4:437-453

3. Allen, Edward P., et al. "Improved technique for localized ridge augmentation: A report of 21 cases." Journal of periodontology 56.4 (1985): 195-199.

4. Misch CE, Judy KW. Classification of partially edentulous arches for implant dentistry.Int J Oral Implantol 1987;4:7-13.

5. Elian, N., S. C. Cho, S. Froum, R. B. Smith and D. P. Tarnow (2007). "A simplified socket classification andrepair technique." Pract Proced Aesthet Dent 19(2): 99-104; quiz 106.

6. Guideline: Cologne Classification of Alveolar Ridge Defects (CCARD). Consensus Paper Approved at the 8th European Consensus Conference (EuCC) in Cologne; February, 2013.

7. Tolstunov L. Classification of the alveolar ridge width: Implant-driven treatment considerations for the horizontally deficient alveolar ridges. J Oral Implantol 2014;40:365-70.

8. Bach Le, Michael D. Rohrer, Hari S. Prassad,Screw "Tent-Pole" Grafting Technique for Reconstruction of Large Vertical Alveolar Ridge Defects Using Human Mineralized Allograft for Implant Site Preparation,Journal of Oral and Maxillofacial Surgery,Volume 68, Issue 2,2010,Pages 428-435.

9. Daga D, Mehrotra D, Mohammad S, Singh G, Natu SM. Tentpole technique for bone regeneration in vertically deficient alveolar ridges: A review. J Oral Biol Craniofac Res. 2015;5(2):92-97.

10. Deeb GR, Tran D, Carrico CK, Block E, Laskin DM, Deeb JG. How Effective Is the Tent Screw Pole Technique Compared to Other Forms of Horizontal Ridge Augmentation? J Oral Maxillofac Surg. 2017 Oct;75(10):2093-2098.
11. Marx RE, Shellenberger T, Wimsatt J, Correa P. Severely resorbed mandible: predictable reconstruction with soft tissue matrix expansion (tent pole) grafts. J Oral Maxillofac Surg. 2002 Aug;60(8):878-88; discussion 888-9.

12. Le B, Burstein J, Sedghizadeh PP. Cortical tenting grafting technique in the severely atrophic alveolar ridge for implant site preparation. Implant Dent. 2008 Mar; 17 :40-50.

13. Korpi JT, Kainulainen VT, Sándor GK, Oikarinen KS. Long-term follow-up of severely resorbed mandibles reconstructed using tent pole technique without Platelet-rich plasma. J Oral Maxillofac Surg. 2012;70(11):2543-2548.

14. Doan, Tu \& Le, Lanh. (2020). Efficacy of the Tent-Pole Technique in Horizontal Ridge Augmentation. Pesquisa Brasileira em Odontopediatria e Clínica Integrada. 20. 10.1590/pboci.2020.109.

15. Işık G, Günbay T, Uyanıkgil Y, Kısaog־lu H, Yüce MÖ. Comparison of Autogenous Block Bone Graft and Screw Tent-Pole Techniques for Vertical Bone Augmentation in the Posterior Mandible: A SplitMouth Randomized Controlled Study. Journal of Advanced Oral Research. 2021;12(1):159-169. 